Tropical Journal of Pharmaceutical Research February 2016; 15 (2): 231-239

ISSN: $1596-5996$ (print); 1596-9827 (electronic)

(C) Pharmacotherapy Group, Faculty of Pharmacy, University of Benin, Benin City, 300001 Nigeria.

All rights reserved.

Available online at http://www.tjpr.org

Original Research Article

http://dx.doi.org/10.4314/tjpr.v15i2.3

\title{
A Holistic In silico Approach to Develop Novel Inhibitors Targeting ErbB1 and ErbB2 Kinases
}

\author{
Jian-Bin $\mathrm{Hu}^{1}$, Ming-Jun Dong ${ }^{2,3}$, Jun Zhang ${ }^{3 \star}$ \\ 'Department of Radiation Oncology, Sir Run Run Shaw Hospital, Sir Run Run Shaw institute of Clinical Medicine of Zhejiang \\ University, Zhejiang University School of Medicine, Hangzhou 310016, ${ }^{2}$ Department of Anus and Intestine, Ningbo no.2 \\ Hospital, Ningbo 315000, ${ }^{3}$ Department of Cardiothoracic Surgery, The PLA 117 Hospital, Hangzhou 310013, China
}

*For correspondence: Email: zhangj310013@gmail.com; Tel/Fax: 0086-571-87964033

Received: 6 July 2015

Revised accepted: 17 December 2015

\begin{abstract}
Purpose: To design a dual inhibitor of natural origin capable of targeting ErbB1 and ErbB2 kinases for the treatment of lung cancer.

Method: Advanced In silico drug designing techniques were explored in this study. Sequence and structure analysis of ErbB1 and ErbB2 was followed by three dimensional (3D) pharmacophore. The generated model was used for molecular docking simulation studies for predicting the best natural dual inhibitors, the selected inhibitors were subjected to absorption, distribution, metabolism, excretion and toxicology (ADME/Tox) prediction.

Results: The results confirmedfive phytochemicals, viz. hyoscyamide, cannabisin $F$, cochinchinenene $D$, cannabisin E, and heliotropamide and five FDA approved drugs namely fesoterodine, antrafenine, fluspirilene, posaconazole, and iloprost to be potential inhibitors of both ErbB1 and ErbB2. The shortlisted compounds from both the panels were showing better MolDock score than the two reference drugs (Lapatinib and Afatinib).

Conclusion: The 3D pharmacophore modelling and molecular docking simulations gave us ten compounds that successfully exploited dual inhibition of ErbB1 and ErbB2. With 8 and 12 hydrogen bonds with ErbB1 and ErbB2 respectively cannabisin F showed best interaction of all.
\end{abstract}

Keywords: Receptor tyrosine kinases, ErbB1, ErbB2, Natural products, Pharmacophore, Docking, Cancer therapy.

Tropical Journal of Pharmaceutical Research is indexed by Science Citation Index (SciSearch), Scopus, International Pharmaceutical Abstract, Chemical Abstracts, Embase, Index Copernicus, EBSCO, African Index Medicus, JournalSeek, Journal Citation Reports/Science Edition, Directory of Open Access Journals (DOAJ), African Journal Online, Bioline International, Open-J-Gate and Pharmacy Abstracts

\section{INTRODUCTION}

The incidence of lung cancer worldwide is $13 \%$. The highest incidence is in developed countries, particularly in North America and Europe, and is less common in developing and underdeveloped countries [1-3]. The etiology of this malady is linked with the anomaly in around 26 genes, among them receptor tyrosine kinases (RTKs), are involved in lung cancer proliferation [4,5]. RTKs belong to epidermal growth factor receptor family and there four structurally related family members are ErbB1 (also known as EGFR or Her1), ErbB2 (also known as Her2 or $\mathrm{Neu}$,), ErbB3 (also known as Her3), and ErbB4 (also known as Her4). Among these, ErbB1 and ErbB2 are predominant in lung cancer [2,6-8]. These kinases have an extracellular ligand binding domain, a single hydrophobic transmembrane domain, and an intracellular tyrosine kinase domain [9]. The success rate of antibody treatment targeting the extracellular ligand binding domain is low [6]. The tyrosine kinase domain, which is structurally conserved in both 
ErbB1 and ErbB2, is the target site for most of the successful anti-cancer drugs which block its kinase activity. Many previous studies have adapted a dual targeting approach-inhibiting ErbB1 and ErbB2 concurrently-which provides synergistic inhibition $[10,11]$. The current study also follows the same approach, but the difference being that we focus on single inhibitor targeting both proteins, unlike the previous approaches which have considered individual inhibitors for each protein.

\section{EXPERIMENTAL}

\section{Protein preparation}

The primary sequences of ErbB1 (UniProt ID: P00533) and ErbB2 (UniProt ID: P04626) were retrieved from Universal Protein Resource (UniProt), which is a comprehensive resource for protein sequence and annotation data. The three-dimensional structures of ErbB1 (PDB ID: 4G5J) and ErbB2 (PDB ID: 3PP0) were obtained from Protein Data Bank (PDB). Although ErbB1 has four isoforms, only the first isoform is primarily involved in lung cancer. ErbB2 has five isoforms. To understand the similarities and dissimilarities of the kinase domain of these isoforms, sequence comparison was performed for each protein separately using the Clustal Omega program of Uniprot. The threedimensional structures of both proteins were compared by jCE algorithm of RCSB PDB Protein Comparison Tool.

\section{Natural product library construction}

Natural products containing 6,160 compounds from marine sources and 18,151 compounds from medicinal plants were retrieved from previous extensive literature studies [12,13], DR. Duke's Phytochemical Library (http://www.arsgrin.gov/duke/), and PubChem BioAssay (http://www.ncbi.nlm.nih.gov/pcassay), which contains the bioactivity screens of chemical substances. Reference approved drug molecules Afatinib (DrugBank ID: DB08916) and Lapatinib (DrugBank ID: DB01259), as well as the 1,543 molecules of FDA approved drugs were obtained from DrugBank (www.drugbank.ca). Since the approved drugs were selected because of their FDA approval, they did not require pre-clinical trials. DrugBank is a comprehensive, highquality, freely accessible, online database containing information on drugs and drug targets.

\section{Ligand preparation and ADME/Tox prediction}

The ligands used for the docking studies were prepared using Maestro version 9.0. It is a robust collection of tools designed to prepare high quality, all-atom 3D structures for large numbers of drug-like molecules, starting with $2 \mathrm{D}$ or $3 \mathrm{D}$ structures in SD or Maestro format. Hydrogens were added to the ligands. The ligand were desalted and tautomers were generated. Specified chiralities of the ligand were maintained. Low energy ring conformation was generated from each ligand. The geometry was optimized using forcefield OPLS 2005. The output file was generated in the sdf file format. QikProp was performed for the natural product molecules obtained from LigPrep. This application was used to determine the Absorption, Distribution, Metabolism, and Excretion (ADME) property. Thirty-one QikProp parameters were considered for each molecule.

It is widely known that QikProp can efficiently evaluate pharmaceutically relevant properties for over half a million compounds in one hour, making it an indispensable lead generation and lead optimization tool. The descriptors considered were number of rotatable bonds, molecular weight, computed dipole moment, total solvent accessible surface area, total solventaccessible volume, number of hydrogen bond donor, number of hydrogen bond acceptor, number of likely metabolic reactions, van der Waals surface area of polar nitrogen and oxygen atoms and carbonyl carbon atoms, predicted central nervous system activity, hexadecane/gas partition coefficient, octanol/gas partition coefficient, water/gas partition coefficient, octanol/water partition coefficient, aqueous solubility, $\mathrm{IC}_{50}$ value for blockage of HERG $\mathrm{K}^{+}$ channels, apparent Caco-2 cell permeability in $\mathrm{nm} / \mathrm{sec}$, apparent MDCK cell permeability in $\mathrm{nm} / \mathrm{sec}$, brain/blood partition coefficient, binding to human serum albumin human oral absorption on 0 to $100 \%$ scale, and conformationindependent predicted aqueous solubility. The molecules that passed ADME prediction were used for Toxpredict procedures. Toxpredict (http://apps.ideaconsult.net:8080/ToxPredict) is a tool from the OpenTox server which calculated the toxicity of the natural product molecules.

\section{D pharmacophore modelling and virtual screening}

A pharmacophore is defined as a 3D structural feature that illustrates the interaction of a ligand molecule with a target receptor in a specific binding site. It is possible to compute the shared pharmacophore feature of a known drug when its three-dimensional structure is available. To this end, virtual screening of the ligand based 3D pharmacophore was performed using LigandScout. The reference drug molecules 
Afatinib (DrugBank ID: DB08916) and Lapatinib (DrugBank ID: DB01259) were optimized by LigPrep of Maestro version 9.0. Both the optimized structures were loaded onto the LigandScout, both structures were then aligned based on the pharmacophore features. Virtual screening was then performed with the generated shared feature against the natural products database and approved drug database created from the molecules obtained from the previous step which are passed from the in silico ADME prediction. The "pharmacophore-fit" scoring function, "match all query features" screening mode, and "get best matching conformation" retrieval mode were used for the pharmacophore search. The screened molecules were further confirmed by docking study.

\section{Molecular docking}

Molecular docking studies were carried out for both the proteins separately with both the datasets natural product and approved drugs using Molegro Virtual Docker (MVD). It has two docking search algorithms: MolDock Optimizer and MolDock Simplex Evolution (SE). MolDock Optimizer is the default search algorithm in MVD. In order to dock the receptor and ligand, the receptor was prepared from the "prepare molecule" option provided. Then, for grid searching, cavities were generated using the "detect cavity" option. Finally, the ligands obtained from the pharmacophore studies were provided in an sdf file format for docking using the docking wizard. Default parameters with the grid resolution of $0.3 \mathrm{~A}$ were employed for elucidating single molecules, capable of inhibiting both the kinases.

\section{Visualization of results}

Molegro Virtual Docker (MVD) software, which is an integrated platform for predicting proteinligand interactions, was used to visualize the docked result. This software handles all aspects of the docking process from preparation of the molecules to determination of the potential binding sites of the target protein, and prediction of the binding modes of the ligands.

\section{RESULTS}

\section{Protein preparation}

The retrieved isoform sequences of ErbB1 and ErbB2 were aligned independently. The kinase domain of isoform1 of ErbB1 did not show any significant similarities with that of the other three isoforms. The kinase domains of all the five isoforms of ErbB2 show significant similarities.
The three-dimensional structures of both proteins were compared by the jCE algorithm. The kinase domains of both proteins showed higher similarity with RMSD: 1.68 , identities: $73 \%$ and similarities: $83 \%$, indicating that a common inhibitor may be inhibiting both the proteins.

\section{ADME/Tox prediction}

It was determined from ADME/Tox prediction that from 24,311 natural product molecules only 1,015 screened out were more poised. The significant reduction in the number of molecules could be attributed to the many stringent descriptors considered for this prediction.

\section{D pharmacophore modelling and virtual Screening}

The structurally optimized drug molecules, Afatinib and Lapatinib, were aligned based on their pharmacophore features using LigandScout. Three shared features - two hydrophobic and one hydrogen bond acceptor were obtained from both the drugs (Fig 1), which were considered as a query for virtual screening.

The 3D pharmacophore virtual screening demonstrated that among the 1,015 ADME passed natural product molecules, only 201 molecules have the pharmacophore features of both drugs, and from the 1527 approved drugs, 356 molecules were matched with the query features. The ensued molecules were further confirmed by docking study.

\section{Molecular docking and toxicity prediction}

The docking studies demonstrated that only 109 of the 201 natural product molecules and 125 of the 356 approved drugs have efficient binding with both the targets. Furthermore, only eighteen natural product molecules and five approved drugs were found to have a better docking score than the reference drug molecules. The twodimensional structure of the reference drug molecules, five best nontoxic natural product molecules and top five FDA approved drug molecules are shown in Figs 2(a) and 2(b).

The MVD docking score is shown in Table 1. The selected phytochemicals had a docking score ranging from $-144.25 \mathrm{Kcal} / \mathrm{mol}$ to -206.72 $\mathrm{Kcal} / \mathrm{mol}$ and the top ranked approved drugs had a docking score ranging from $-139.98 \mathrm{Kcal} / \mathrm{mol}$ to $-201.28 \mathrm{Kcal} / \mathrm{mol}$, which is better than that of the reference drug molecules. 
The docking result with hydrogen bond interactions are shown in Figs. 3(a) and 3(b). The number of hydrogen bonds and the interacting residues are shown in Tables 2 and 3.

The reference drug molecules had one to four hydrogen bond interactions with the target. More importantly, the shortlisted phytochemicals and FDA approved drugs had six to twelve and one to eight hydrogen bond interactions, respectively. The docking score and number of hydrogen bonds of natural products and FDA approved drugs demonstrated higher affinity with proteins than the reference drug molecules. Furthermore, a detailed analysis of the docking results showed that all ligands bonded with the kinase domains of the target.
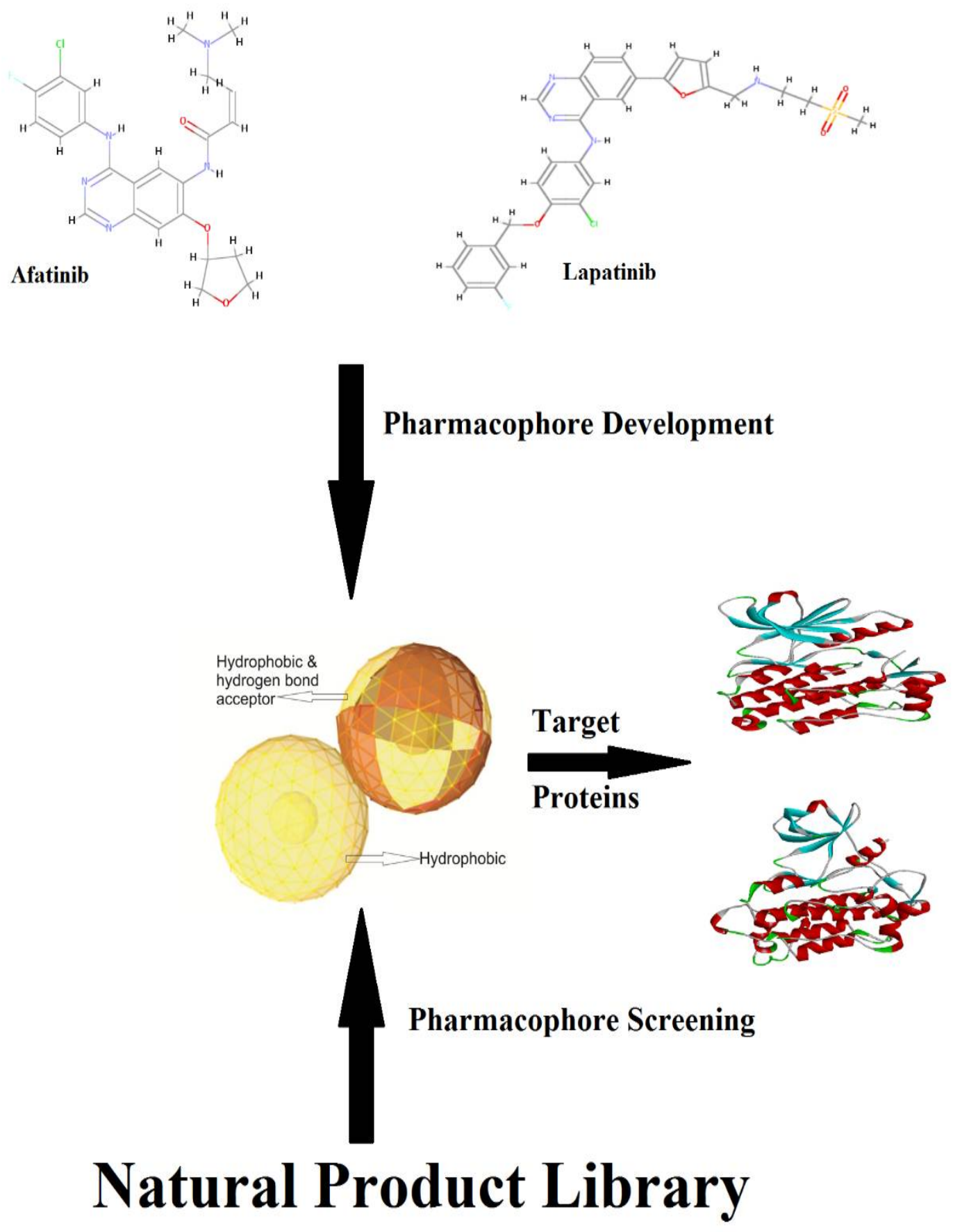

Figure 1: The modus operandi used in the study, from pharmacophore development to virtual screening to molecular docking 


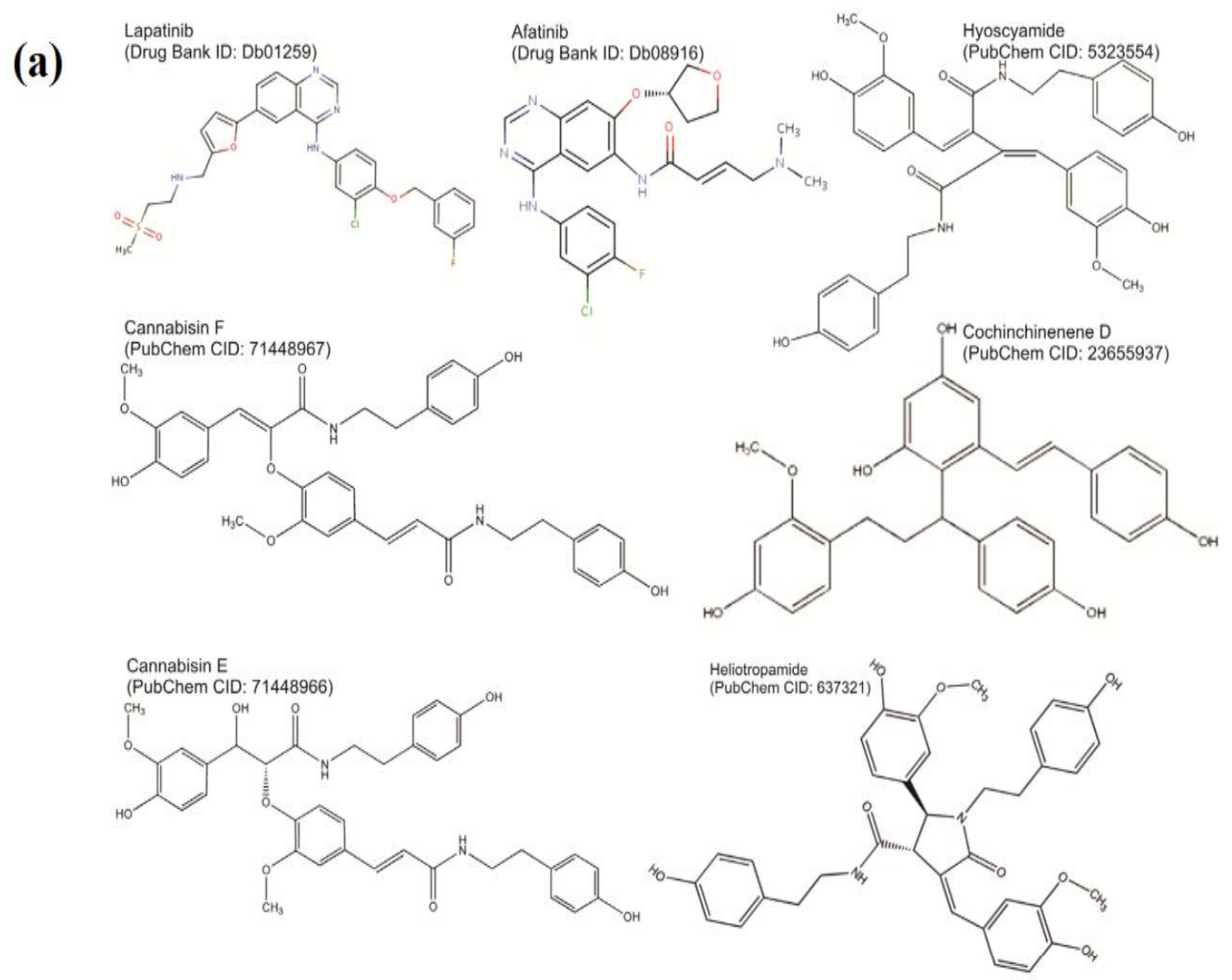

(b)

Fesoterodine (Drug Bank ID: DB06702)<smiles>CC(C)C(=O)Oc1ccc(CO)cc1[C@H](CCN(C(C)C)C(C)C)c1ccccc1</smiles>

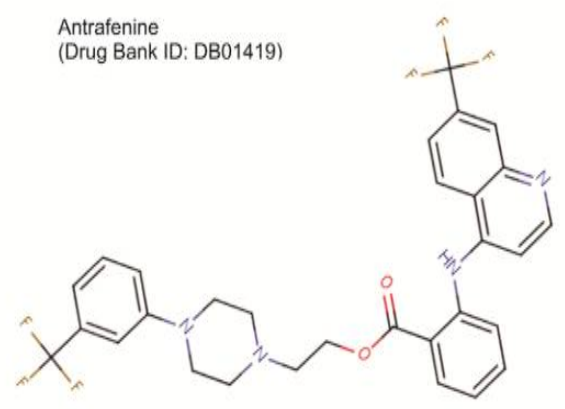

$$
\begin{aligned}
& \text { Fluspirilene } \\
& \text { (Drug Bank ID: DB04842) }
\end{aligned}
$$

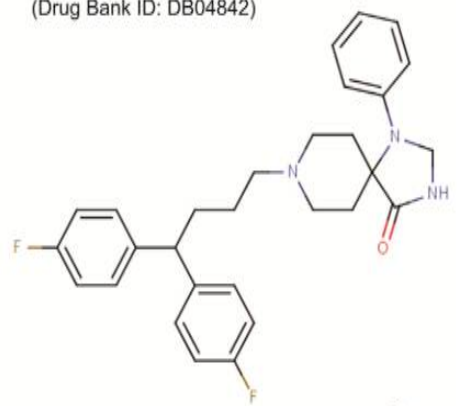

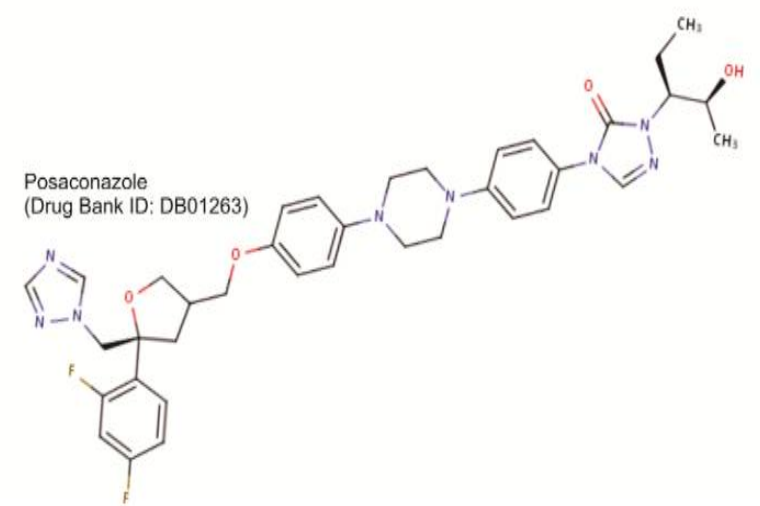

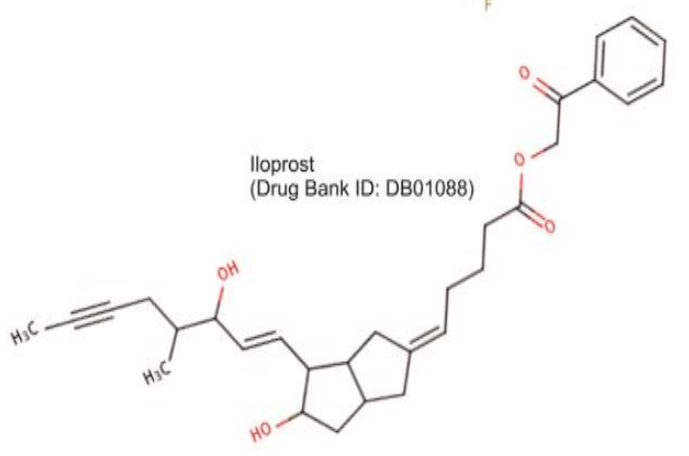

Figure 2: (a) Two dimensional structure of reference drug molecules and the selected phytochemicals (b) Two dimensional structure of selected top five FDA approved drugs 
Table 1: Docking score of reference drug molecules, phytochemicals, and top five FDA approved drugs with ErbB1 and ErbB2

\begin{tabular}{|c|c|c|c|c|c|c|c|}
\hline \multirow{2}{*}{$\begin{array}{l}\text { Name } \\
\text { Reference Drug }\end{array}$} & \multirow{2}{*}{$\begin{array}{l}\text { DrugBank ID / } \\
\text { PubChem CID }\end{array}$} & \multicolumn{3}{|c|}{ ErbB1 } & \multicolumn{3}{|c|}{ ErbB2 } \\
\hline & & $\begin{array}{l}\text { MolDock } \\
\text { Score } \\
\text { (Kcal/mol) }\end{array}$ & $\begin{array}{c}\text { Rerank } \\
\text { Score }\end{array}$ & HBond & $\begin{array}{l}\text { MolDock } \\
\text { Score } \\
\text { (Kcal/mol) }\end{array}$ & $\begin{array}{c}\text { Rerank } \\
\text { Score }\end{array}$ & HBond \\
\hline Lapatinib & DB01259 & -143.61 & -111.05 & -0.46 & -180.07 & -154.09 & 0.34 \\
\hline Afatinib & DB08916 & -135.62 & -94.54 & -1.08 & -171.46 & -145.83 & -4.73 \\
\hline \multicolumn{8}{|l|}{ Phytochemicals } \\
\hline Hyoscyamide & CID 5323554 & -169.50 & -107.91 & -12.96 & -206.72 & -151.38 & -12.67 \\
\hline Cannabisin F & CID 71448967 & -152.04 & -102.19 & -3.22 & -203.89 & -129.93 & -5.98 \\
\hline Cochinchinenene D & CID 23655937 & -153.32 & -12.82 & -18.04 & -192.07 & -145.30 & -11.08 \\
\hline Cannabisin E & CID 71448966 & -144.25 & -80.66 & -12.30 & -184.77 & -134.13 & -0.58 \\
\hline Heliotropamide & CID 637321 & -166.11 & -103.16 & -4.53 & -180.75 & -89.20 & -6.94 \\
\hline \multicolumn{8}{|c|}{ FDA Approved drugs } \\
\hline Fesoterodine & DB06702 & -283.38 & -67.59 & -3.09 & -201.28 & -103.16 & -9.52 \\
\hline Antrafenine & DB01419 & -155.33 & -106.60 & -0.86 & -201.03 & -164.84 & -1.07 \\
\hline Fluspirilene & DB04842 & -139.98 & -86.12 & -0.36 & -190.66 & -153.02 & -5.89 \\
\hline Posaconazole & DB01263 & -141.70 & -91.79 & -4.41 & -190.55 & -120.98 & -6.10 \\
\hline Iloprost & DB01088 & -147.13 & -48.72 & -5.00 & -189.66 & -150.88 & -2.35 \\
\hline
\end{tabular}

Table 2: Number of hydrogen bonds and interacting residues from the docking result of reference drug molecules and phytochemicals

\begin{tabular}{|c|c|c|c|c|}
\hline \multirow[t]{2}{*}{ Name } & \multicolumn{2}{|r|}{ ErbB1 } & \multicolumn{2}{|r|}{ ErbB2 } \\
\hline & $\begin{array}{c}\text { Number of } \\
\text { Hydrogen } \\
\text { Bonds }\end{array}$ & Interacting residues & $\begin{array}{l}\text { Number of } \\
\text { Hydrogen } \\
\text { Bonds }\end{array}$ & Interacting residues \\
\hline Lapatinib & 1 & Lys 728 & 3 & Ala 771, Gly 804, Thr 862 \\
\hline Afatinib & 1 & Met 793 & 4 & $\begin{array}{c}\text { Gly } 727 \text {, Met } 801 \text {, Cys } 805, \text { Asp } \\
808\end{array}$ \\
\hline Hyoscyamide & 9 & $\begin{array}{l}\text { Gly } 719, \text { Ser } 720, \text { Lys } \\
\text { 745, Cys } 775, \text { Thr } 790 \text { ( } 2 \\
\text { hbonds), Gln } 791, \\
\text { Thr } 854, \text { Asp } 855\end{array}$ & 7 & $\begin{array}{l}\text { Leu 726, Gly 804, Cys } 805 \text { (3 } \\
\text { hbonds), Glu 812, Arg } 849\end{array}$ \\
\hline Cannabisin F & 8 & $\begin{array}{l}\text { Lys 745, Glu 762, Cys } \\
\text { 797, Asp 800, Asn 842, } \\
\text { ASP } 855 \text { (3 hbonds) }\end{array}$ & 12 & $\begin{array}{c}\text { Gly } 729 \text {, Ala 751, Lys } 753 \text {, Leu } \\
\text { 796, Val 797, Thr 798, Gln 799, } \\
\text { Leu 800, Met 801, Asp 808, Glu } \\
\text { 812, Asp } 863\end{array}$ \\
\hline $\begin{array}{l}\text { Cochinchinenene } \\
\text { D }\end{array}$ & 10 & $\begin{array}{l}\text { Lys } 745 \text {, Cys } 775, \text { Thr790, } \\
\text { Gln 791, Met 793, Gly } \\
\text { 796, Asn } 842, \text { Thr } 854, \\
\text { Asp 855,(2 hbonds) }\end{array}$ & 6 & $\begin{array}{c}\text { Ser 728, Lys 753, Met } 801 \text { (2 } \\
\text { hbonds), Arg 849, Asn } 850\end{array}$ \\
\hline Cannabisin $\mathrm{E}$ & 7 & $\begin{array}{c}\text { Gly 719, Lys 728, Pro } \\
\text { 794, Cys } 797 \text { (2 hbonds), } \\
\text { Asp } 800, \text { His } 805\end{array}$ & 11 & $\begin{array}{c}\text { Leu 726, Gly 727, Gly 729, Tyr } \\
\text { 803, Cys } 805 \text { ( } 2 \text { hbonds), Asp } \\
\text { 808, Glu 812, Arg 849, Asn 850, } \\
\text { Thr } 862\end{array}$ \\
\hline Heliotropamide & 7 & $\begin{array}{c}\text { Lys 745, Pro 794, Cys } \\
\text { 797, Asp } 800 \text { ( } 2 \text { hbonds), } \\
\text { Asn } 842 \text {, Asp } 855\end{array}$ & 6 & $\begin{array}{l}\text { Ser } 728, \text { Gly } 729, \text { Met } 801 \text { ( } 2 \\
\text { hbonds), Gly } 804 \text {, Cys } 805\end{array}$ \\
\hline
\end{tabular}


Table 3: Number of Hydrogen Bonds and Interacting residues from the docking result of top five FDA approved drugs

\begin{tabular}{|c|c|c|c|c|}
\hline \multirow[t]{2}{*}{ Name } & \multicolumn{2}{|r|}{ ErbB1 } & \multicolumn{2}{|r|}{ ErbB2 } \\
\hline & $\begin{array}{l}\text { Number } \\
\text { of } \\
\text { Hydrogen } \\
\text { Bonds }\end{array}$ & Interacting residues & $\begin{array}{l}\text { Number of } \\
\text { Hydrogen } \\
\text { Bonds }\end{array}$ & Interacting residues \\
\hline Fesoterodine & 3 & $\begin{array}{c}\text { Arg 841, Asn 842, Asp } \\
855\end{array}$ & 2 & Thr 798, Gln 799 \\
\hline Antrafenine & 1 & Cys 797 & 2 & Gly 729, Arg 849 \\
\hline Fluspirilene & 1 & Asp 855 & 5 & $\begin{array}{c}\text { Ala 751, Lys 753, Leu 796, Thr 862, } \\
\text { Asp } 863\end{array}$ \\
\hline Posaconazole & 4 & $\begin{array}{l}\text { Asp 837, Asn 842, Asp } \\
855 \text { ( } 2 \text { hbonds) }\end{array}$ & 8 & $\begin{array}{c}\text { Ser } 783 \text { (2 hbonds), Arg 784, Leu } \\
\text { 785, Thr 798, Arg 811, Thr 862, Asp } \\
863\end{array}$ \\
\hline lloprost & 2 & Lys 745, Thr 854 & 4 & Ser 728 (2 hbonds), Val 797, Thr 798 \\
\hline
\end{tabular}

(a)
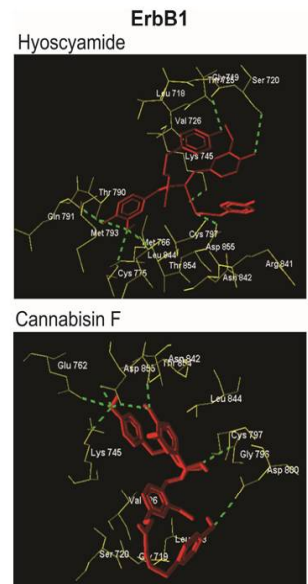

Cochinchinenene D
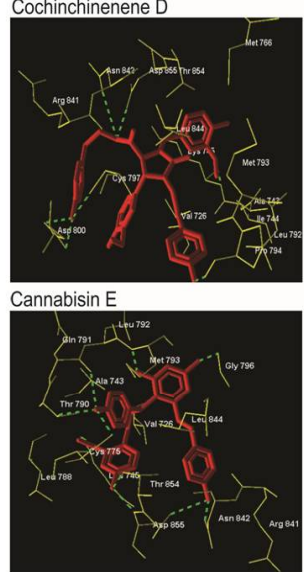

Heliotropamide
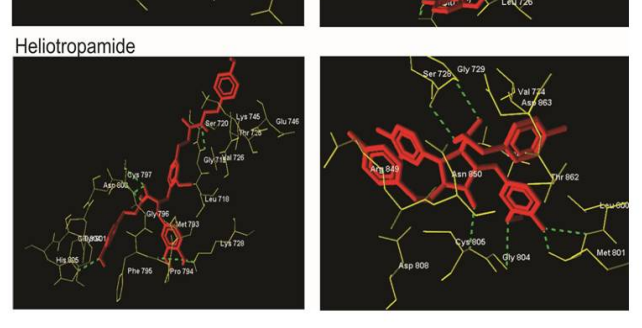

(b)
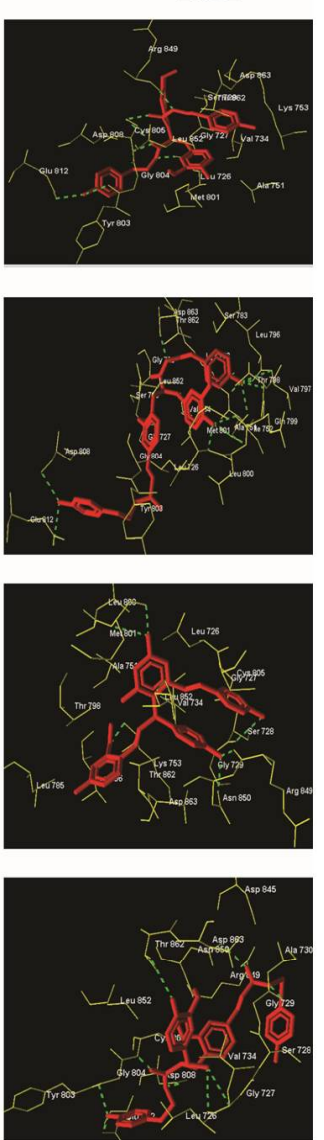
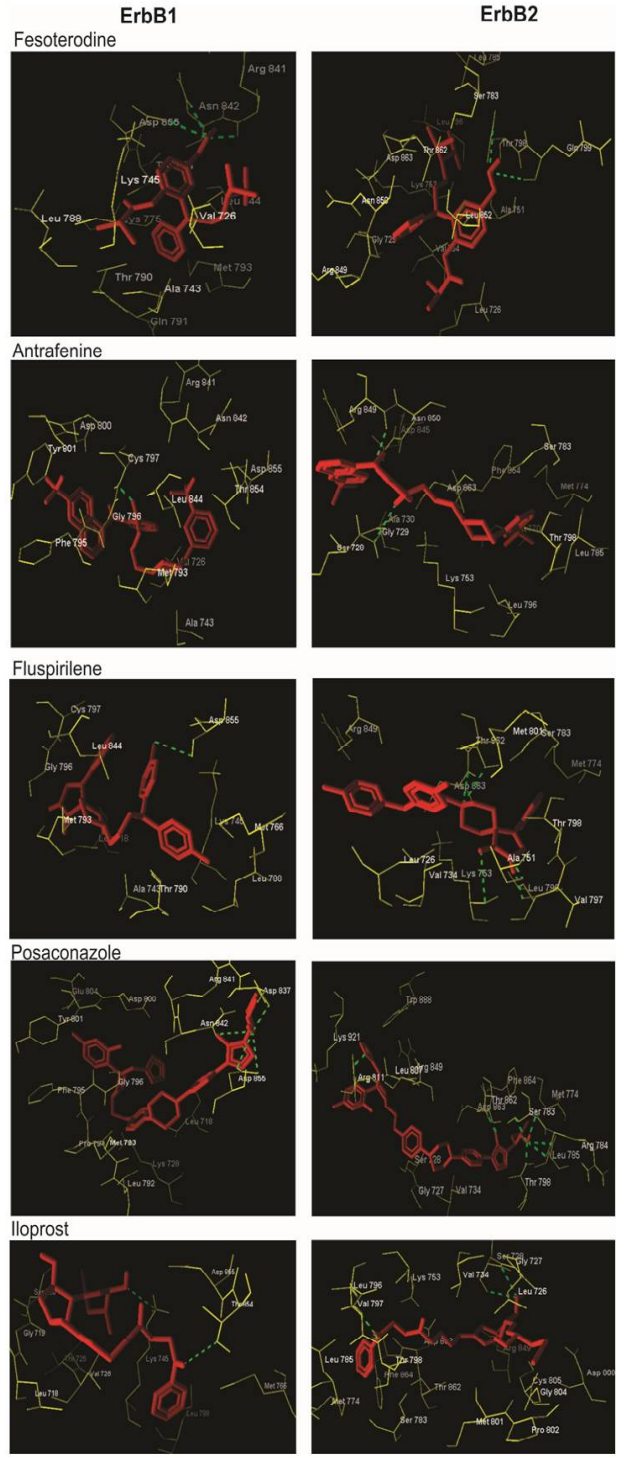

Figure 3: (a) Docking results of phytochemicals with ErbB1 and ErbB2 (b) Docking results of top five FDA approved drugs with ErbB1 and ErbB2 


\section{DISCUSSION}

Molecular docking has played a key role in the identification of efficient binding of receptors and ligands. Compounds identified from docking studies with most favourable binding energy were considered as hits. Hyoscyamide, a secondary metabolite present in the seeds of Hyoscyamus niger is binding to ErbB1 and ErbB2 with MolDock score of $-169.5(\mathrm{kcal} / \mathrm{mol})$ and $-206.7(\mathrm{kcal} / \mathrm{mol})$ respectively. Hyoscyamide binding energy is the least calculated among the top ten compounds with ErbB2. The hydrogen bond forming pattern is nine hydrogen bonds with ErbB1 and seven with ErbB2. Cannabisin F and Cannabisin E are acyclic bis-phenylpropane lignanamides existing in the fruits of Cannabis sativa. Cannabis sativa is cultivated for seed oil, food, and medicine. Historically, tinctures, tea, and ointments have also been common preparations. In traditional Indian medicine, $\boldsymbol{C}$. sativa has been used as a hallucinogenic, hypnotic, sedative, an analgesic, and antiinflammatory agent [14]. Cannabisin E is binding to ErbB1 and ErbB2 with MolDock score of $144.2(\mathrm{kcal} / \mathrm{mol})$ and $-184.7(\mathrm{kcal} / \mathrm{mol})$, the hydrogen bond pattern with the two kinases is seven and eleven respectively. Cannabisin F is the best compound among shortlisted phytochemicals in terms of hydrogen bond pattern. Cannabisin $\mathrm{F}$ is forming eight hydrogen bonds with ErbB1 and twelve with ErbB2. Recently, a group of scientists from China synthesized cannabisin $F$ from vanillin [15]. Cannabisin $\mathrm{F}$ has already been reported for its cytotoxic activity [16], and cell-growth inhibitory activities against human lung cancer and human cervical cancer [17]. Cochinchinenene D from Dracaena cochinchinensis has already been reported for its antibacterial activities against Helicobacter pylori [18], Dracaena cochinchinensis is predominant in China and its various other secondary metabolites are used to cure a variety of diseases, including neurodegenerative diseases, diabetes, and cancer $[19,20]$. Cochinchinenene $D$ is forming the best interaction with ErbB1 of ten hydrogen bonds, which is the best among the analyzed twelve compounds. Heliotropamide from Heliotropium ovalifolium has oxopyrrolidine-3carboxamide central moiety. Heliotropamide among the selected phytochemicals is showing the least number of interaction with ErbB1 and ErbB2 (seven and six).

The hydrogen bond binding pattern of the FDAapproved drugs is overall lower than phytochemicals. Fesoterodine, which is an approved drug, a prodrug is showing the best binding energy of $-283.3(\mathrm{kcal} / \mathrm{mol})$ with ErbB1.
The compound have no reported anti-cancer activity, however its in vivo broken down active metabolite: 5-hydroxymethyl tolterodine (5-HMT) exhibits an antimuscarinic activity by acting as a competitive muscarinic receptor antagonist, Both urinary bladder contraction and salivation are mediated via cholinergic muscarinic receptors [21]. Antrafenine is a piperazine derivative drug that acts as an analgesic and anti-inflammatory with an efficacy similar to that of naproxen, the compound is showing second best binding energy with ErbB2 among FDA-approved drugs and has not been reported for anti-cancer activity. Fluspirilene is a relatively long-acting injectable depot antipsychotic drug used for schizophrenia. It does not differ greatly from other depot antipsychotics (fluphenazine decanoate, fluphenazine enathate, perphenazine onanthat, pipotiazine undecylenate) with respect to treatment efficacy, response, or tolerability. Fluspirilene is showing the least potential for inhibiting the selected kinases among the ten shortlisted compounds. Posaconazole among the FDA-approved drugs is showing the best hydrogen bond interaction with both ErbB1 and ErbB2. The compound exerts its antifungal activity through blockage of the cytochrome $\mathrm{P}$ 450 dependent enzyme, sterol 14a-demethylase, in fungi by binding to the heme cofactor located on the enzyme, this leads to the inhibition of the synthesis of ergosterol, a key component of the fungal cell membrane, and accumulation of methylated sterol precursors, which in turn results in the inhibition of fungal cell growth, and ultimately, cell death [22]. lloprost is a second generation structural analog of prostacyclin (PGI) with about tenfold greater potency than the first generation stable analogs, such as carbaprostacyclin. The compound is forming two and four hydrogen bonds with ErbB1 and ErbB2 respectively, which is second best interaction among FDA-approved drugs.

\section{CONCLUSION}

The in silico approach has helped us to predict promising compounds for targeting ErbB1 and ErbB2 kinases with single inhibitor for the effective treatment of lung cancer. The approach provides an opportunity to focus only on selected compounds for further wet-lab experimental analysis.

The generated data of the ten compounds show immense potential in targeting both kinases with single inhibitor. All the selected lead compounds are non-toxicity, the factor that has an immense role in drug discoveries. 


\section{ACKNOWLEDGEMENT}

The authors would like to acknowledge the bioinformatics department of Sir Run Run Shaw Hospital for providing us with the tools for the study.

\section{REFERENCES}

1. Siegel R, Ma J, Zou Z, Jemal A. Cancer statistics, 2014. CA: a cancer journal for clinicians 2014; 64(1): 9-29.

2. Sharma SV, Bell DW, Settleman J, Haber DA. Epidermal growth factor receptor mutations in lung cancer. Nature Rev Cancer 2007; 7(3): 169-181.

3. Siegel $R$, Naishadham $D$, Jemal $A$. Cancer statistics, 2012. CA: a cancer journal for clinicians 2012; 62(1): 10 29.

4. El-Telbany A, Ma PC. Cancer Genes in Lung Cancer: Racial Disparities: Are There Any? Genes \& Cancer 2012; 3(7-8):467-80. doi: 10.1177/1947601912465177. PubMed PMID: 23264847; PubMed Central PMCID: PMCPmc3527990.

5. Wilhelm SM, Carter C, Tang L, Wilkie D, McNabola A, Rong $H$, et al. BAY 43-9006 exhibits broad spectrum oral antitumor activity and targets the RAF/MEK/ERK pathway and receptor tyrosine kinases involved in tumor progression and angiogenesis. Cancer research 2004; 64(19):7099-109.

6. Hynes NE, Lane HA. ERBB receptors and cancer: the complexity of targeted inhibitors. Nature Rev Cancer 2005; 5(5): 341-354.

7. Robinson DR, Wu Y-M, Lin S-F. The protein tyrosine kinase family of the human genome. Oncogene 2000; 19(49): 5548-5557.

8. Yarden $Y$, Pines G. The ERBB network: at last, cancer therapy meets systems biology. Nature Rev Cancer 2012; 12(8): 553-563.

9. Wood ER, Truesdale AT, McDonald OB, Yuan D, Hassell $A$, Dickerson $S H$, et al. A unique structure for epidermal growth factor receptor bound to GW572016 (Lapatinib) relationships among protein conformation, inhibitor offrate, and receptor activity in tumor cells. Cancer research 2004; 64(18): 6652-6659.

10. Tebbutt N, Pedersen MW, Johns TG. Targeting the ERBB family in cancer: couples therapy. Nature Rev Cancer 2013; 13(9): 663-673.
11. Singla S, Pippin JA, Drebin JA. Dual ErbB1 and ErbB2 receptor tyrosine kinase inhibition exerts synergistic effect with conventional chemotherapy in pancreatic cancer. Oncol Reports 2012; 28(6): 2211-2216.

12. Mayer AM, Gustafson KR. Marine pharmacology in 2003-2004: anti-tumour and cytotoxic compounds. Eur J Cancer 2006; 42(14):2241-2270.

13. Mayer AM, Gustafson KR. Marine pharmacology in 2005-2006: Antitumour and cytotoxic compounds. Eur J Cancer 2008; 44(16): 2357-2387.

14. Wang L, Waltenberger B, Pferschy-Wenzig E-M, Blunder $M$, Liu X, Malainer $C$, et al. Natural product agonists of peroxisome proliferator-activated receptor gamma (PPARY): a review. Biochem Pharmacol 2014; 92(1): 73-89.

15. Xia Y-M, Xia J, Chai C. Total synthesis of cannabisin F. Chemical Papers 2014; 68(3):384-91.

16. Chen J-J, Huang S-Y, Duh C-Y, Chen I-S, Wang T-C, Fang $H-Y$. A new cytotoxic amide from the stem wood of Hibiscus tiliaceus. Planta Medica 2006; 72(10): 935.

17. Li YZ, Tong AP, Huang J. Two new norlignans and a new lignanamide from Peperomia tetraphylla. Chem Biodiver 2012; 9(4): 769-776.

18. Zhu Y, Zhang P, Yu H, Li J, Wang M-W, Zhao W. AntiHelicobacter pylori and thrombin inhibitory components from Chinese dragon's blood, Dracaena cochinchinensis. Journal of natural products 2007; 70(10): 1570-577.

19. Li N, Ma Z, Li M, Xing Y, Hou Y. Natural potential therapeutic agents of neurodegenerative diseases from the traditional herbal medicine Chinese Dragon's Blood. Journal of ethnopharmacology 2014; 152(3): 508-521.

20. Fan J-Y, Yi T, Sze-To C-M, Zhu L, Peng W-L, Zhang $Y$-Z, et al. A Systematic Review of the Botanical, Phytochemical and Pharmacological Profile of Dracaena cochinchinensis, a Plant Source of the Ethnomedicine "Dragon's Blood". Molecules 2014; 19(7): 10650-10669.

21. Malhotra B, Gandelman K, Sachse R, Wood N, Michel M. The design and development of fesoterodine as a prodrug of 5-hydroxymethyl tolterodine (5-HMT), the active metabolite of tolterodine. Curr Medicin Chem2009; 16(33): 4481-4489.

22. Schiller DS, Fung HB. Posaconazole: an extendedspectrum triazole antifungal agent. Clinical therapeutics 2007; 29(9): 1862-1886. 